frontal lobe, which was localized and removed by Starr and McBurney.

For those practitioners, who by force of circumstances are expected to be proficient in all departments of medicine, the last chapter, devoted to the operation of trephining, is likely to prove the most valuable in the book. It has been revised by Dr. McBurney, and the technique, which is minutely described, is the result of the most recent advances in this realm of surgery.

H. P. DeForest, M.D. (Brooklyn).

Lessoxs in Phisical Diagnosis. By Alfred L. Loomis, M.D.,

LL.D. Tenth edition, revised and enlarged. Svo., 240 pages.

New York: Willianı Wood \& Company.

This book upon Physical Diagnosis by Dr. Loomis is too well and favorably known to need any detailed description as to its scope and character. The tenth edition has just appeared, and in the prefatory note the author says that it has been thoroughly revised. Upon careful examination, however, one regrets that the revision has not been more complete, and that a book which has so many good qualities should also have so nany glaring defects. When it is compared with a work like the recent one by Wesener, upon the same subject, and designed for the same purpose, i. e., a complete and concise guide for both student and practitioner, the inferior quality of Dr. Loomis' book is all the more a]parent.

The main portion of the book is devoted to the physical examination of the thoracic viscera, and here the author appears to the best advantage. His style is concise, his opinions positive.

In the other chapters the same high standard is not maintained. To point out in detail all of the errors and omissions is undesirable, yet some of them should certainly be mentioned. The chief subject which one would naturally expect to find in such a work, and which is omitted, is physical diagnosis as applied to the more common forms of nervous diseases; the ophthalmoscope is dwelt upon at some 
length, as well as a few other instruments of minor importance in the diagnosis of these diseases, and this completes the subject.

In the chapter deroted to mechanical aids in the diagnosis of diseases the instruments described are those in rogue ten years ago; modern inprovements are rarely referred to. The many ingenious and valuable appliances in which the electric light is used as an aid in the examination of the accessible carities of the body are not described. The endoscope is named only, but the cy'stoscope is not. Four lines are deroted to the entire subject of specula for the ear, vagina, rectum and urethra. The microscope and its use are hastily. described, the use of the condenser is omitted, as well as other important details. An instrument so linited in its sphere as the Liebreich ophthalmoscope can be recommended only on the ground of cheapness. There are better stethoscopes to-day than the one "derised by the late Dr. Cammann." The nasal speculum of which a picture is given has been superseded by better ones. Certainly the best sphygnograph is not that of Marey. Even the thermometer represented is a poor one, and the method " of repeated sudden blows of the wrist upon the knee" is not to be recommended. There are a number of good pulse tracings given, but no temperature curves-a fact which detracts materially from the value of the section devoted to the range of temperature in health and in disease. A page of plates representing the typical laryngeal images would be of great assistance to the beginner in laryngoscopy.

The chapter upon the examination of urine is an improvement upon the ones in previons editions, but still there are many new and valuable tests omitted, while others of little use are retained.

Similar errors and important omissions are found throughont the book.

The book is better printed than previous editions, and while most of the illustrations are only passable, those taken from the drawings by Dr. Byron and reproduced in colors are well executed and of value. The photograph of the Filaria samminis hominis is especially good. 
Against our inclination we are forced to conclude that the book is one which adds to the difficulties which a physician has to contend with when he tries to select a working library, When a medical work is first published it usually embodies the most recent and advanced ideas upon the subject discussed, but if one prefers books of the older writers, and buys the so-called "revised editions," in many cases he finds the revision is incomplete, not up to date, and generally unsatisfactory. Examples are numerous. How many of the revised editions of the various "surgeries" published will give the practitioner an accurate working knowledge of modern aseptic surgical technique ? Which of the "standard chemistries" will satisfy the desire of a person seeking information concerning recent achievements in synthetical manufacture? The sale of many of these books is large, not becanse of their real current value, but because of the rejutation of the author, gained years ago. 'The effect of the sale is bad. If they fall into the hands of a student, he starts in his practice handicapped by the use of inaccurate books of reference; if the old practitioner buys them, thinking thus to keep in touch with the best work of the day, he soon detects the many errors, the book is laid awa;, he regrets the useless expense, and the author loses one more of his former admirers.

H. P. DE FOKEEI (Brooklyn).

\section{TO CONTRIBUTORS AND SUBSCRIBERS.}

All Contributions for Publication, Books for Review and Exchanges should be sent to the Editorial Office, $1+5$ Gates Avenue, Browklys, X. Y.

Remittances for Subscriptions and Advertising, and all business conmunications should be addressed to the

LNIVERSITY OF PEXXSYLVANIA PRESS, I516 Chestout Street,

Philadelphia, $\mathrm{Pa}$. 